\title{
A "Dialética da Malandragem” em Lalino Salãthiel e João Grilo
}

\author{
Evelin Guedes ${ }^{1}$
}

RESUMO: Apoiado no ensaio "Dialética da Malandragem - caracterização das Memórias de um Sargento de Milícias" de Antonio Candido e na sua definição da figura do malandro, este artigo propõe uma análise das personagens de Guimarães Rosa e Ariano Suassuna, respectivamente, Lalino Salãthiel e João Grilo como protótipos do malandro brasileiro. Para tanto esquadrinharemos os seus percursos em suas narrativas, bem como demonstraremos que as suas ligações à clássica novela picaresca e à commedia dell'arte não passam de referências.

ABSTRACT: Bases in the essay "Dialética da Malandragem - caracterização das Memórias de um Sargento de Milícias" of Antonio Candido and his definition of the trickster figure, this article aims to make an analysis of the characters of Guimarães Rosa and Ariano Suassuna respectively Lalino Salãthiel and João Gilo as prototypes of the Brazilian trickster. In order to do so, we will analyze both their paths in their narratives, as well as demonstrate that their connections to the classic picaresque novel and the commedia dell'arte are just references.

PALAVRAS-CHAVE: Ariano Suassuna; Guimarães Rosa; Malandro; Literatura brasileira. KEYWORDS: Ariano Suassuna; Guimarães Rosa; Trickster; Brazilian literature.

No ensaio intitulado "Dialética da Malandragem - caracterização das Memórias de um Sargento de Milícias" (CANDIDO, 1970, p. 67-89), Antonio Candido, afirma que a personagem de Leonardo do livro de Manuel Antônio de Almeida constitui

o primeiro grande malandro que entra na novelística brasileira, vindo de uma tradição quase folclórica e correspondendo, mais do que se costuma dizer, a certa atmosfera cômica e popularesca de seu tempo, no Brasil. (CANDIDO, p. 71).

Assim, inaugura-se na literatura brasileira toda uma genealogia da malandragem, da qual acreditamos descender Lalino Salãthiel, personagem de Guimarães Rosa do

\footnotetext{
${ }^{1}$ Mestre em Literatura Oral e Tradicional e Doutoranda em Estudos Brasileiros na Universidade de Lisboa com a tese Contradições produtivas na obra romanesca de Ariano Suassuna: nacionalismo e herança portuguesa. Membro e colaboradora do Centro de Literaturas e Culturas Lusófonas e Europeias (CLEPUL). Contato: evelinba@hotmail.com
} 
conto “A Volta do Marido Pródigo" (ROSA, 1994, p. 244-277) e o João Grilo criado por Ariano Suassuna para o Auto da Compadecida (SUASSUNA, 1998).

Neste estudo, sob a luz da caracterização da figura do malandro definida por Antonio Candido, analisaremos estas personagens através do esquadrinhamento dos seus percursos em suas narrativas específicas, bem como demonstraremos que as suas ligações à clássica novela picaresca e à commedia dell'arte não passam de referências que estão gravadas na superfície das suas epidermes, não constituindo, portanto, as suas essências. Essas, em Lalino e João Grilo, afirmam a sua fíliação ao protótipo do malandro brasileiro.

Ao pormos em confronto estas duas personagens, o dado que primeiro chama a atenção, é o fato de serem contemporâneas. Eulálio de Souza Salãthiel é apenas nove anos mais velho que João Grilo, uma vez que "A Volta do Marido Pródigo", inserido em Sagarana, foi publicado em 1946 e o Auto da Compadecida em 1955. Esta informação ultrapassa o limite da frivolidade, pois ambas as narrativas, ao dedicarem-se à crítica social, com a distância de menos de uma década, discursam sobre um cenário político e socioeconômico comum, guardadas as devidas peculiaridades regionais. Embora a história de Lalino passe por um curto período na cidade, a maior parte da narrativa está centrada no sertão de Minas Gerais. Com João Grilo toda a ação dá-se no sertão da Paraíba. O que nos interessa neste ensaio é marcar o espaço do Sertão, pois nele a estrutura de organização social é similar, o que nos permitirá compreender o funcionamento e as escolhas das personagens em questão. Ao debruçarmo-nos sobre a sua análise percebemos que, em geral, a tradição da teoria literária tende a defini-las como representantes do pícaro (no caso do Lalino) e do arlequim (João Grilo), embora muitos também definam a personagem suassuniana como um pícaro, o que não é de todo um equívoco, uma vez que Rosa e Suassuna, no decorrer da narrativa e para o leitor informado e atento, deixam algumas pistas a respeito desta ligação com a novela picaresca e com a commedia dell'arte, respectivamente. O que se pode notar, principalmente, no âmbito da estrutura da construção das personagens, mas ao esquadrinharmos essa ligação com a tradição europeia, vemos que essa é mais uma das máscaras que os autores utilizam para ludibriar o leitor com a intenção, de construírem, através dos recursos disponíveis na tradição, a imagem do malandro.

Segundo Antonio Candido, não se pode considerar uma personagem como pícaro se a ela "faltam as marcas peculiares do gênero picaresco" (CANDIDO, p. 67). Tomando a personagem do conto de Guimarães Rosa vê-se que a tradição que defende 
Lalino como representante da novela picaresca espanhola, supervaloriza algumas analogias. De fato, a análise da picaresca espanhola em confronto com as obras aqui discutidas revela que é possível que Ariano Suassuna e Guimarães Rosa tenham retirado da picaresca hispânica algumas sugestões marginais para a construção das suas personagens, no entanto sugestões ou contaminações literárias não são elementos satisfatórios para definir personagens. Para equacionar essa questão vejamos a análise dos pontos de convergência e divergência entre as personagens aqui em estudo e a caracterização clássica da picaresca espanhola seguida da figura do arlequim da commedia dell'arte.

\section{O pícaro clássico, o arlequim, Lalino Salãthiel e João Grilo:} pontos de convergência

As características principais da novela picaresca são as que mais interessam para este trabalho e, ao observá-las, vemos que tanto Lalino quanto João Grilo encaixam-se, parcialmente, na definição do pícaro. Ambos pertencem a uma classe social desprovida, embora não seja dada ao leitor informações sobre as suas origens, o que aponta para uma aproximação com a picaresca de tradição hispânica: a inexatidão quanto à origem. A vida errante e trapaceira, cheia de artimanhas, é o mote das narrativas de "A Volta do Marido Pródigo" e do Auto da Compadecida, o que pode ser visto como uma espécie de eco da novela picaresca espanhola. A condição servil também é outro elemento em comum e que está ligada intimamente à habilidade de empreender ardis astuciosos na luta pela sobrevivência "passando de amo a amo o pícaro vai-se movendo, mudando de ambiente, variando a experiência e vendo a sociedade no conjunto, o que permite uma sondagem dos grupos sociais e seus costumes" (CANDIDO, p. 70). O que reflete a vida de Lalino e Grilo. Eulálio de Souza Salãthiel começa como operário de construção na rodovia Belo Horizonte - São Paulo; com a sua ida para o Rio de Janeiro, dá-nos a entender que fica desempregado, ao retornar torna-se cabo eleitoral do Major Anacleto, além disso, dava aulas de violão para a mulher de seu Waldemar, motorista do caminhão da empresa de rodagem; no Auto, João Grilo tem apenas um patrão, o padeiro, contudo está sempre a prestar 'serviços' a outros em busca de alguns trocados. Assim, ambos conseguem transitar perfeitamente entre as camadas sociais e, ao perceber o mecanismo que as movimenta, estabelecem conchavos e alianças em proveito próprio, através da sua inteligência, astúcia e artimanha. Essa variação de 
atividades profissionais está intimamente ligada à mudança de condição social e representa um anseio típico das personagens relacionadas ao poder da linguagem, da artimanha, da astúcia, características do romance picaresco.

As narrativas sobre os ardis dos seus protagonistas são o que constituem os textos de Rosa e Suassuna. Em “A Volta do Marido Pródigo" Lalino tem sempre uma maneira de se esquivar de suas obrigações, burlar a todos, e, ainda assim, manter certo prestígio. Muitas vezes mal-intencionado, utiliza-se de máscaras sociais para conseguir driblar o trabalho, valendo-se da ingenuidade alheia. Parte de pequenas artimanhas até a sua grande negociata: a 'venda' da sua mulher, a fim de arranjar dinheiro para ir ao Rio de Janeiro. Ação que despoleta o primeiro ponto de virada da narrativa. O segundo será o retorno ao arraial e o contrato como cabo eleitoral do Major Anacleto, quando inicia uma sequência de estratagemas que demonstram o domínio da linguagem de Lalino e o seu poder de persuasão para uma função específica no texto, a crítica social. O que é outro ponto de interseção com a picaresca hispânica: a sátira social.

Com João Grilo a estrutura é parecida, no entanto a sua análise requer um entendimento a priori. Quem se dedica a estudar a obra de Ariano Suassuna tem como dado adquirido a intertextualidade que o autor mantém com o Romanceiro tradicional ibérico, detectável em toda a sua produção literária. Sendo assim, não é de surpreender que João Grilo não seja uma criação suassuniana, é antes uma recriação, uma vez que esse personagem chega ao Brasil vindo da Península Ibérica oriundo dos contos tradicionais portugueses, sendo, posteriormente, acoplado ao repertório folclórico nordestino.

o João Grilo que encontramos nos contos populares portugueses [...] em nada se parece com o nosso endiabrado, inteligente e ardiloso João Grilo nordestino em que o transformamos. O personagem de um dos mais conhecidos contos da tradição oral portuguesa é um tolo, um falso adivinhão favorecido pelas circunstâncias. (LOPES, 1996, p. 77).

A modificação do caráter da personagem, que 'espertou' ao atravessar o Atlântico, justifica-se através do processo de aculturação, quando João Grilo ganhou características idênticas às de outro famoso espertalhão, também de origem ibérica: Pedro Malazarte. Este, segundo Câmara Cascudo, "é figura tradicional nos contos populares da Península Ibérica, como exemplo de burlão invencível, astucioso, cínico, inesgotável de expedientes e de enganos, sem escrúpulos e sem remorsos" (1954, p. 
518). A opção pelo caráter de Malazarte, em oposição ao de mais um tolo que vive ao sabor da sorte, justifica-se em uma região como o sertão, onde a opressão do clima e das relações humanas, sociais, políticas e econômicas rege a vida do sertanejo. Assim, entende-se que a tradição tenha escolhido como representante do povo um personagem com capacidades argutas que luta pela sua sobrevivência, enganando os poderosos representantes da classe que o oprime, obtendo algum sucesso em suas investidas, o que cria no povo uma espécie de empatia e identificação com João Grilo, que é visto, ainda que apenas na ficção, como um herói que consegue prover-se mesmo diante da situação de miséria e abandono na qual está inserido.

O João Grilo de Suassuna, embora seja um tipo autenticamente brasileiro, possui também alguns traços do arlequim da commedia dell'arte. A linha que separa as nuances de caráter entre o pícaro e o arlequim é muito tênue. Acreditamos que o principal divisor entre o arlequim e o pícaro é a comicidade atribuída ao arlequim. Nesse sentido, ao analisarmos Lalino Salãthiel em oposição a João Grilo, percebe-se rapidamente a diferença. Lalino não é cômico por natureza, é a personificação do esperto, apenas em algumas situações provoca o riso, mas não tende ao ridículo, à hilaridade ou ao grotesco, traços característicos do arlequim e de João Grilo.

Outro traço do arlequim que podemos constatar em João Grilo diz respeito à construção da personagem como aquele que articula a trama e convida à reflexão através da oralidade do seu discurso coloquial. É assim que João Grilo se comporta: está sempre em cena e é quem provoca e resolve o conflito. A escolha de alegorizar a fala e o visual da personagem com um discurso irônico e carnavalizado, firmemente radicado no popular, permite um tom de repúdio e de revolta contra a realidade social facilmente assimilado por indivíduos de realidades e interesses díspares. $\mathrm{O}$ arlequim utiliza um tom satírico e cômico sem usar de vulgaridade ou agressividade, que é exatamente a linguagem empregada por João Grilo.

\section{O pícaro clássico, o arlequim, Lalino Salãthiel e João Grilo: pontos de divergência}

Um ponto fundamental da picaresca hispânica que não encontramos em nenhuma das narrativas é a estrutura de falsa autobiografia, narrada em primeira pessoa que aparece no romance como autor e como ator. Como autor situa-se num tempo presente que olha para o seu passado e narra uma ação cujo desenlace conhece de 
antemão, o que não acontece nem em Rosa e nem em Suassuna. O conto rosiano é narrado em $3^{\text {a }}$ pessoa e o narrador é onisciente; no texto suassuniano não há um narrador, há a figura do palhaço, mas apenas na abertura da peça para apresentar a história e as personagens. O tempo da peça é o presente, João Grilo não está a narrar o seu passado, nem domina o desenlace da história. Sobre as genealogias das personagens também não há nenhuma informação, como já referimos.

O determinismo é mais um fator que nega a aproximação dessas obras à picaresca clássica. Na novela hispânica, embora o pícaro tente melhorar de condição social, fracassa sempre. Por conta disso a estrutura do romance picaresco é aberta, visto que as aventuras narradas poderiam continuar indefinidamente, pois não há evolução possível que mude a história. Diante da análise feita neste estudo sobre Lalino e João Grilo, vê-se perfeitamente que isso não se aplica às suas trajetórias. Ambos são premiados no final das narrativas, tendo as suas histórias uma estrutura fechada. O que também vai apontar para outro fator de divergência entre as narrativas rosiana e suassuniana com a picaresca hispânica: a ideologia moralizante e pessimista, na qual seu protagonista ou se arrepende dos seus pecados ou será castigado. O pícaro é assim visto como um pecador arrependido, um anti-herói. "De fato, um elemento importante da picaresca é essa espécie de aprendizagem que amadurece e faz o protagonista recapitular a vida à luz de uma filosofia desencantada" (CANDIDO, p. 69). Essa trajetória de arrependimento e aprendizagem não se verifica nas personagens rosiana e suassuniana. Em “A Volta do Marido Pródigo", Lalino Salãthiel, embora queira reconquistar Maria Rita, não se revela arrependido nem se sente pecador por ter 'vendido' a mulher. Na peça suassuniana, isto fica evidente na cena do julgamento, em que João Grilo justifica todos os seus 'pecados' por conta da sua condição social, sem também revelar nenhum arrependimento ou aprendizagem.

Mais um traço básico do pícaro falta às personagens: o choque áspero com a realidade, que leva à mentira, à dissimulação, ao roubo, e constitui a maior desculpa das picardias. De acordo com Antonio Candido, "na sua origem o pícaro é ingênuo; a brutalidade da vida é que aos poucos o vai tornando esperto e sem escrúpulos, quase como defesa" (CANDIDO, p. 69); no entanto, a propensão à picardia em Lalino e em João é quase um exercício de exibicionismo das suas inteligências, pode-se mesmo ler nas entrelinhas certo grau de satisfação quando os seus ardis funcionam. Parecem demonstrar que desse modo vingam a sua pobreza, ao defraudar os poderosos, utilizando-se apenas da sua astúcia. Em Lalino e em João Grilo, a mentira, o roubo, as 
artimanhas são como se se tratasse de uma qualidade essencial, não um atributo adquirido por força das circunstâncias. A mudança no destino de João Grilo e de Lalino Salãthiel com um desenlace positivo para ambos já é a primeira sinalização da construção do tipo do malandro, que sempre obtém êxito no final.

O fator de divergência entre João Grilo e o arlequim da commedia dell'arte, está no fato de João extrapolar a função básica do personagem, que se restringia a divertir o público durante os intervalos dos espetáculos. João Grilo é o protagonista da narrativa e, embora esteja imbuído de forte comicidade, não é o 'bobo-da-corte', é um tipo autenticamente brasileiro.

Não há imitação servil ou mera transposição, mas autêntica recriação em termos brasileiros, tanto pela ambientação como pela estruturação, sendo uma obra inédita em suas características, nova e, portanto, absolutamente original. O seu encanto está nesse ar de ingenuidade que a caracteriza, na singeleza dos recursos empregados, no primarismo do argumento, tudo a nosso ver perfeitamente dentro do espírito popular em que a obra se inspira e que quer manter. (OSCAR, p.10).

\section{A construção da figura do Malandro}

Diante do exposto, é possível afirmar que Lalino Salãthiel e João Grilo constituem uma espécie do tipo do malandro oriundo de uma tradição quase folclórica. Segundo Antonio Candido "o malandro, como o pícaro, é espécie de um gênero mais amplo de aventureiro astucioso, comum a todos os folclores" (CANDIDO, p. 71). Com efeito, tanto Lalino quanto João, praticam a astúcia pela astúcia, pelo jogo em si, pelo exercício da malandragem, o que faz com que estas personagens se distancieme do antiherói pícaro e se aproximem dos traços de heróis populares, como Pedro Malazarte. O que parece predominar nas características de Lalino Salãthiel e João Grilo é o dinamismo próprio dos astuciosos da história popular, logo, "algo mais vasto e intemporal, próprio da comicidade popularesca" (CANDIDO, p. 72). Pode-se dizer que as narrativas de Rosa e de Suassuna possibilitam uma associação íntima entre a representação dos costumes das sociedades retratadas em cada uma das narrativas e os traços folclóricos das personagens, manifestados, sobretudo, através dos seus atos e 
peripécias, que, por sua vez, baseiam-se na "intuição da dinâmica social do Brasil" (CANDIDO, p. 73).

No rastro desse pensamento, vemos que em “A Volta do Marido Pródigo" e no Auto da Compadecida há um universo que parece liberto do peso do erro e do pecado. Alguns podem destacar que no texto suassuniano o conceito de pecado existe, tanto que há a cena do julgamento, mas, ao analisar em profundidade esta cena, vê-se que a discussão que se faz sobre o pecado não é dicotômica tanto assim que o 'maior pecador', o Capitão Serafim, assassino, não é condenado de imediato por Manuel.

\section{MANUEL}

Acuse Severino e o cabra dele.

ENCOURADO

E precisa? São dois cangaceiros conhecidos. Mataram mais de trinta. [...] Acho que basta. Inferno nele.

\section{MANUEL}

Espere, isso também não é assim de repente não! Davi fez coisa muito pior, traindo o amigo com a mulher e mandando ainda por cima o pobre morrer na guerra e, no entanto, era meu avô e grande amigo meu, um santo de quem você não tem coragem nem de pronunciar o nome. (SUASSUNA, p. 158-59).

Ambos os textos revelam uma ausência de culpabilidade e repressão, tanto dos seus protagonistas para com a sua história, como da de alguns personagens para com eles, pois, ao se afastar do par bem/mal, cria-se uma balança de equilíbrio. No ambiente onde circula o tipo do malandro "os referidos pares são reversíveis, não estanques, e fora da racionalização ideológica as antinomias convivem num curioso lusco-fusco" (CANDIDO, p. 86). Segundo Antonio Candido há ainda "uma espécie de curiosidade superficial" (CANDIDO, p. 85) dos personagens uns pelos outros, o que forma a trama das relações narradas:

A esta curiosidade corresponde uma visão muito tolerante, quase amena. As pessoas fazem coisas que poderiam ser qualificadas como reprováveis, mas fazem também outras dignas de louvor, que as compensam. E como todos têm defeitos, ninguém merece censura. (CANDIDO, p. 85). 
Desta forma, nos textos de João Guimarães Rosa e de Ariano Suassuna, os seus respectivos malandros, Lalino e João Grilo, adotam um princípio de moral que, em suma, é

uma espécie de balanceio entre o bem e o mal, compensados a cada instante um pelo outro sem jamais aparecerem em estado de inteireza. Decorre a ideia de simetria ou equivalência, que, numa sociedade meio caótica, restabelece incessantemente a posição por assim dizer normal de cada personagem. Os extremos se anulam e a moral dos fatos é tão equilibrada quanto as relações dos homens. [...] O remorso não existe, pois a avaliação das ações é feita segundo a sua eficácia. [...] criando uma espécie de terra-de-ninguém moral, onde a transgressão é apenas um matiz na gama que vem da norma e vai ao crime. (CANDIDO, p. 86).

É o que verificamos tanto na cena do julgamento, como também na absolvição de todos, inclusive, de João Grilo. O perdão de Lalino por parte de Maria Rita e a sua promoção social (ao tornar-se cabo eleitoral do Major Anacleto), também se encaixam na assertiva de Antonio Candido. Ambos os malandros (rosiano e suassuniano) são recompensados no final das narrativas, o que é perfeitamente esclarecido por Antonio Candido quando afirma que

No Brasil, nunca os grupos ou os indivíduos tiveram a obsessão da ordem senão como princípio abstrato, nem da liberdade senão como capricho. As formas espontâneas da sociabilidade atuaram com maior desafogo e por isso abrandaram os choques entre a norma e a conduta, tornando menos dramáticos os conflitos de consciência. (CANDIDO, p. 87-88)

Isto ilustra perfeitamente a elaboração do tipo do malandro tanto na figura de Lalino Salãthiel quanto na de João Grilo, construída a partir de uma costela originalmente folclórica e baseada em estruturas de cunho arquetípico.

Por fim, concluímos que é ponto pacífico a aproximação de alguns traços das personagens rosiana e suassuniana com a picaresca hispânica e com a commedia dell'arte, no entanto, como já afirmamos neste estudo, não se pode considerar uma personagem como picaresca, se a ela "faltam as marcas peculiares do gênero picaresco" (CANDIDO, p. 67). Seguindo esse raciocínio, não podemos falar em uma filiação e representação destes modelos em Lalino Salãthiel ou em João Grilo, são mais ecos do que filiação. Essas são personagens genuinamente brasileiras, calcadas na matriz 
folclórica do Brasil que constitui outro tipo, o malandro. Acreditamos que não nos devemos referir ao pícaro Lalino ou ao arlequim/pícaro João Grilo, mas sim aos malandros brasileiros Lalino e Grilo. É a essa genealogia que pertencem os personagens de Guimarães Rosa e Ariano Suassuna.

\section{Referências Bibliográficas:}

CANDIDO, Antonio. "Dialética da Malandragem - caracterização das Memórias de um Sargento de Milícias" in Revista do Instituto de Estudos Brasileiros, São Paulo, USP, 1970, no 8 , p. 67-89.

CASCUDO, Luís da Câmara. Dicionário do folclore brasileiro. 3.ed., Rio de Janeiro: Tecnoprint, 1954.

LOPES, Ribamar. Cordel - Mito e Utopia. Maranhão, Série Coleção Cidade de São Luís: s/ed., vol. 1, 1996.

OSCAR, Henrique. "Prefácio" in SUASSUNA, Ariano. Auto da Compadecida. 33.ed., Rio de Janeiro, Agir, 1998.

ROSA, João Guimarães. "A Volta do Marido Pródigo" in Ficção completa em dois volumes, Rio de Janeiro, Nova Aguilar, 1994, 2. vol., p. 244-277.

SUASSUNA, Ariano. Auto da Compadecida. 33.ed., Rio de Janeiro, Agir, 1998. - Uma dramaturgia da impureza, da mistura. Entrevista a Márcio Marciano e Sérgio de Carvalho. Revista Vintém: Ensaios para um Teatro Dialético. São Paulo: Hucitec, n. 2. maio/junho/julho de 1998a, p. 2-8. 